\title{
The Effects of APOE and ABCA7 on Cognitive Function and Alzheimer's Disease Risk in African Americans: A Focused Mini Review
}

\author{
Chelsie N. Berg*, Neha Sinha and Mark A. Gluck* \\ Center for Molecular and Behavioral Neuroscience, Rutgers University-Newark, Newark, NJ, United States
}

African Americans have double the prevalence of Alzheimer's disease (AD), as compared to European Americans. However, the underlying causes of this health disparity are due to a multitude of environmental, lifestyle, and genetic factors that are not yet fully understood. Here, we review the effects of the two largest genetic risk factors for AD in African Americans: Apolipoprotein E (APOE) and ABCA7. We will describe the direct effects of genetic variation on neural correlates of cognitive function and report the indirect modulating effects of genetic variation on modifiable AD risk factors, such as aerobic fitness. As a means of integrating previous findings, we present a novel schematic diagram to illustrate the many factors that contribute to $A D$ risk and impaired cognitive function in older African Americans. Finally, we discuss areas that require further inquiry, and stress the importance of racially diverse and representative study populations.

Reviewed by:

Ferath Kherif,

Lausanne University Hospital (CHUV), Switzerland Jose Marcelo Farfel, University of São Paulo, Brazil

${ }^{*}$ Correspondence: Chelsie N. Berg chelsienberg@gmail.com Mark A. Gluck gluck@newark.rutgers.edu

Specialty section This article was submitted to Health, a section of the journal Frontiers in Human Neuroscience

Received: 31 May 2019 Accepted: 16 October 2019 Published: 05 November 2019

Citation: Berg CN, Sinha N and Gluck MA (2019) The Effects of APOE and $A B C A 7$ on Cognitive Function and Alzheimer's Disease Risk in African Americans: A Focused Mini Review.

Front. Hum. Neurosci. 13:387. doi: 10.3389/fnhum.2019.00387

Keywords: African American (AA), APOE $\varepsilon 4, A B C A 7$, aerobic fitness, cognitive function, cognitive decline, Alzheimer's disease

\section{INTRODUCTION}

African Americans are at an elevated risk of cognitive decline and memory loss, with double the prevalence of Alzheimer's disease (AD) as compared to European Americans (Logue et al., 2011; Barnes and Bennett, 2014; Alzheimer's Association, 2019). The underlying causes of this health disparity are not sufficiently understood. Apolipoprotein E (APOE) and ABCA7, two genes involved in lipid metabolism, are the strongest heritable contributors to AD in African Americans (Reitz et al., 2013). However, the influence of genetic risk on environmental and behavioral risk factors, and their combined effects on AD biomarkers in African Americans, is yet to be determined. Furthermore, little is known about the neural substrates of cognition in older African Americans and how they relate to genetic risk factors for AD.

Here, we review recent work outlining two distinct ways genetic risk impacts AD biomarkers in African Americans. First, we examine the direct effects of genetic variation on neural correlates of cognitive function, such as activation and functional connectivity from functional magnetic resonance imaging (fMRI) studies. Second, we discuss the indirect effects of genetics on brain structure and function, via interaction with modifiable risk factors for $\mathrm{AD}$, specifically aerobic fitness.

African Americans are at an increased risk of cardiovascular disease (Obisesan et al., 2012), which has been established as an important predictor for $\mathrm{AD}$ (Izquierdo-Porrera and Waldstein, 2002). Management or improvement of cardiovascular risk factors through increased aerobic 
fitness and exercise can reduce the risk for cognitive decline and dementia (Baumgart et al., 2015). Consistent with this, low levels of physical activity is one of the most prevalent risk factors for AD (Norton et al., 2014; Cass, 2017). In particular, African Americans have lower rates of physical activity as compared to European Americans (Gothe and Kendall, 2016; Benjamin et al., 2019). As such, aerobic fitness and exercise may be more viable modifiable factors to attenuate the risk for $\mathrm{AD}$ in African Americans.

It is important to delineate the difference between $\mathrm{AD}$ as determined by neuroimaging, biofluid biomarkers, or autopsy, as compared to the clinical diagnosis of Alzheimer's and related dementias. However, to remain aligned with the terminology of the original cited works, throughout this review we refer to both instances as $\mathrm{AD}$.

\section{DIRECT EFFECTS OF GENETICS}

\section{APOE}

The APOE $\varepsilon 4$ allele is one of the strongest genetic risk factors for $\mathrm{AD}$ (Potter and Wisniewski, 2012). APOE functions to regulate lipid metabolism in the brain by mediating the uptake of lipoproteins; in particular, it modulates the clearance of amyloid- $\beta$ (A $\beta$; Di Paolo and Kim, 2011). Both dysfunctional cholesterol processing and $A \beta$ aggregation have been implicated in $\mathrm{AD}$ pathogenesis (Schultz et al., 2017). In European Americans, the APOE $\varepsilon 4$ allele has been associated with 2-3 times the risk of $\mathrm{AD}$ in heterozygotes and 12 times the risk in homozygotes (Michaelson, 2014). African Americans have a higher frequency of the APOE $\varepsilon 4$ allele (Logue et al., 2011; Barnes and Bennett, 2014), and $\varepsilon 4$ homozygosity is highly associated with $\mathrm{AD}$ in African-ancestry groups (Hendrie et al., 2014). However, the results are inconsistent for heterozygotic carriers (Farrer et al., 1997), with some studies suggesting that APOE \&4 may have less predictive impact on AD outcomes in African-ancestry populations, including African Americans (Rajabli et al., 2018). Despite the mixed nature of these findings, APOE $\varepsilon 4$ has been associated with increased risk of late onset AD (LOAD) in African Americans (OR $=2.31$; 95\% increased risk; Reitz et al., 2013).

APOE $\varepsilon 4$ has also been linked to episodic memory-related dysfunction in the medial temporal lobe (MTL; Bookheimer et al., 2000; Filippini et al., 2009; Dennis et al., 2010; Michaelson, 2014), one of the earliest brain regions impacted by the progression of $\mathrm{AD}$. APOE $\varepsilon 4$ genotype and amyloid-induced synaptic pathology have been related to accelerated rates of AD pathology within the MTL (Potter and Wisniewski, 2012), particularly in hippocampal sub-regions in both rodent and human models (Palmer and Good, 2011).

Pattern separation-the ability to independently represent and store similar experiences by reducing mnemonic interference (Leal and Yassa, 2018)-relies on MTL function. As such, one way to characterize decline into mild cognitive impairment (MCI) and $\mathrm{AD}$ is by a shift away from pattern separation towards pattern completion, which is mediated by dysfunctional hippocampal hyperactivity (Yassa et al., 2011b). Impaired mnemonic discrimination is associated with atypical hyperactivation in the dentate gyrus (DG) and CA3 hippocampal subfields (Dickerson et al., 2005; Yassa et al., 2011a,b; Reagh et al., 2017) in healthy older adults (Toner et al., 2009; Stark et al., 2013) and those with MCI (Yassa et al., 2010; Bakker et al., 2012, 2015; Tran et al., 2017).

Research examining the impact of APOE $\varepsilon 4$ genotype on MTL function, via performance on a mnemonic discrimination task, has yielded mixed results in different racial populations with varying degrees of cognitive impairment. A study in MCI patients reported no differences in hippocampal hyperactivation or mnemonic discrimination based on APOE $\varepsilon 4$ status (Tran et al., 2017). Conversely, AD patients that were homozygotic carriers of the APOE $\varepsilon 4$ allele performed worse on challenging mnemonic discriminations (Wesnes et al., 2014). When examining spatial mnemonic discrimination across cognitively impaired and unimpaired older adults, impaired $\varepsilon 4$ carriers performed worse than unimpaired carries and either group of non-carriers (Sheppard et al., 2016).

These previous studies were primarily conducted in European American cohorts and/or did not report the specific racial breakdown of their subject pools. In a population of cognitively healthy older African Americans, there were APOE $\varepsilon 4$-related impairments in mnemonic discrimination, coincident with hyperactivity in the left DG/CA3 and the CA1. Although the overall effect of APOE $\varepsilon 4$ on AD outcomes in African Americans remains unclear (Farrer et al., 1997; Tang et al., 2001; Hendrie et al., 2014; Rajabli et al., 2018), this result may suggest that APOE $\varepsilon 4$-related hippocampal dysfunction can manifest in healthy older African Americans and may be an indicator of future disease status.

While $\mathrm{APOE} \varepsilon 4$ is associated with a moderately increased risk for progression from MCI to AD-type dementia (EliasSonnenschein et al., 2011), it may not alter the disease progression during the preclinical period (Bondi et al., 1999; Bunce et al., 2004). However, the effect of APOE $\varepsilon 4$ in the preclinical phase may be contingent on other factors such as the level of amyloid aggregation (Mormino et al., 2014) and homozygotic vs. heterozygotic status (Caselli et al., 1999). Clinically normal carriers of APOE $\varepsilon 4$ with high levels of amyloid aggregation experienced the highest levels of cognitive decline as compared to $\varepsilon 4$ non-carriers and those with lower $\mathrm{A} \beta$ aggregation (Mormino et al., 2014). Cognitively healthy APOE $\varepsilon 4$ homozygotic carriers also experienced memory decline earlier than heterozygotic carriers (Caselli et al., 1999).

\section{ABCA7}

Outside of APOE, ABCA7 is the strongest genetic risk factor for AD in African Americans (Reitz et al., 2013). As a member of the super-family of adenosine triphosphate (ATP)-binding cassette $(\mathrm{ABC})$ transporters, $\mathrm{ABCA} 7$ is another gene that regulates the homeostasis of phospholipids and cholesterol in the central nervous system and peripheral tissues. ABCA7 gene expression has been linked to AD via the dysregulation of lipid metabolism (Zhao et al., 2015; Aikawa et al., 2018).

ABCA7 single nucleotide polymorphism (SNP) rs115550680 is associated with the development of LOAD in African Americans with an effect size (OR $=1.79 ; 70 \%-80 \%$ 
increase in risk) that is comparable to that of APOE $\varepsilon 4$ (Reitz et al., 2013). ABCA7 rs115550680 is hypothesized to contribute to $\mathrm{AD}$ in African Americans through amyloid precursor protein (APP) processing and the suppression of $\mathrm{A} \beta$ clearance (Cukier et al., 2016).

In cognitively healthy elderly subjects and MCI patients, cortical $A \beta$ load is associated with disrupted functional connectivity within the MTL and impaired memory performance (Song et al., 2015). As such, $A \beta$ plaques may play a key role in facilitating tauopathy in the MTL, and therefore lead to disrupted functional connectivity in the MTL circuitry. Hardy and Selkoe (2002) suggest that one of the functions of ABCA7 in AD may be $\mathrm{A} \beta$ facilitated tauopathy: as $\mathrm{A} \beta$ deposition accumulates in cortical regions within the default mode network (DMN), it may lead to concurrent accumulation of tau tangles in the MTL via reciprocal connections through the entorhinal cortex (EC) (Pooler et al., 2015). Hence, the cortico-MTL circuit may be the neural network underlying ABCA7 rs115550680-related AD pathology.

A recently published study examining the impact of ABCA7 rs115550680 genotype on the cortico-MTL network function in a group of cognitively healthy older African Americans found ABCA7-related dissociation in EC resting state functional connectivity (Sinha et al., 2019). Specifically, the risk variant was associated with increased functional connectivity between the EC and other MTL regions, including hippocampal subfields, coincident with decreased connectivity between the EC and medial prefrontal cortex (mPFC; Sinha et al., 2019). These findings suggest that for individuals with the risk ABCA7 rs115550680 genotype, impaired cortical connectivity leads to a more functionally isolated EC at rest, which translates into aberrant EC-MTL hyper-synchronization (Sinha et al., 2019).

While direct claims cannot be made about the exact mechanism underlying the aforementioned alterations in cortico-MTL network function, when considering the relevance of $\mathrm{A} \beta$ in $\mathrm{ABCA7}$-related $\mathrm{AD}$ pathogenesis, these results may reflect the combined reinforcement between amyloid and tau pathology in the EC (Sinha et al., 2019). Thus, anomalous MTL functional connectivity may be an additional neural correlate of future cognitive decline in African Americans. This ABCA7 variant is monomorphic in European Americans (Reitz et al., 2013; Machiela and Chanock, 2015), and consequently, it does not confer any increased risk for $\mathrm{AD}$ in this group. However, recent studies of functional connectivity in MCI and $\mathrm{AD}$ patients have reported a similar disconnection of the MTL from other nodes of the DMN, particularly mPFC, but increased connectivity locally within the MTL, between EC and other subregions of the MTL (Das et al., 2013; Pasquini et al., 2015). As such, MTL network dysfunction may be a ubiquitously applicable $\mathrm{AD}$ biomarker for preclinical $\mathrm{AD}$ detection.

\section{INDIRECT EFFECTS OF GENETICS}

\section{The Interaction With Aerobic Fitness}

Modifiable lifestyle factors, such as diet, exercise, and aerobic fitness, contribute to $\mathrm{AD}$ risk. In particular, aerobic fitness is one cardiovascular disease management method that has been associated with decreased levels of cognitive decline and reduced risk of $\mathrm{AD}$ in several previous studies (Colcombe and Kramer, 2003; Kramer et al., 2005, 2006). Aerobic activity has been found to aid in brain lipid homeostasis and in the reduction of $\mathrm{A} \beta$ deposit accumulation (Maesako et al., 2012; He et al., 2017; Houdebine et al., 2017). Recent work has also argued that increased levels of aerobic fitness can attenuate the adverse influence of AD-related polygenic vulnerability derived from genes implicated in lipid homeostasis, including APOE and ABCA7 (Schultz et al., 2017).

In addition to ABCA7 rs115550680 (reviewed under Direct Effects of Genetics), which has been identified as a genetic risk factor for AD in African Americans, another ABCA7 SNP (rs3764650) has been identified as a susceptibility locus for AD in European Americans (Hollingworth et al., 2011; Naj et al., 2011). ABCA7 rs3764650 has a lower effect size in African Americans $(\mathrm{OR}=1.23)$, increasing $\mathrm{AD}$ risk by about 10\%-20\% (Reitz et al., 2013). However, this SNP has been found to influence overall ABCA7 expression (the conversion of DNA instructions into functional products and proteins), and, dysfunctional ABCA7 expression levels are associated with AD risk (Vasquez et al., 2013; Aikawa et al., 2018).

While the overall effects of ABCA7 rs3764650 on cognition seem to be minimal (Vivot et al., 2015; Andrews et al., 2016, 2017), it has been found to alter cognition in subgroups stratified on factors such as gender and disease progression. In healthy elderly, an association between rs3764650 and cognitive decline was found selectively in females (Nettiksimmons et al., 2016), and, in individuals with a final diagnosis of MCI or AD, this SNP was associated with increased rates of memory decline (Karch et al., 2012; Carrasquillo et al., 2015).

A study of healthy older African Americans found that ABCA7 rs3764650 modulates the association between aerobic fitness level (as measured by maximal oxygen consumption, $\mathrm{VO}_{2} \max$ ) and mnemonic flexibility - the ability to flexibly apply and recombine information from past learning-as measured by generalization following rule learning (Berg et al., 2019). In particular, for carriers of the non-risk genotype, higher levels of aerobic fitness were significantly associated with fewer generalization errors. Conversely, carriers of the risk genotype did not show any relationship between aerobic fitness and generalization. Successful mnemonic flexibility is known to depend on the integrity of the MTL (Myers et al., 2002, 2008), a major site of neuroplasticity that is sensitive to the effects of exercise and aerobic fitness (Cotman et al., 2007). The results of Berg et al. (2019) therefore imply that the ABCA7 risk genotype may attenuate the neuro-protective value of aerobic fitness in cognitively healthy older African Americans.

Analogous to this study, others have found that in European Americans, APOE $\varepsilon 4+$ individuals did not receive the same benefits as APOE $84-$ individuals from higher levels of aerobic fitness or following an exercise intervention, with fitness only reducing the risk for dementia in non-carriers (Podewils et al., 2005; Lautenschlager et al., 2008). On the contrary, some self-reported studies of physical activity found that the neuroprotective effects of fitness were exclusive to APOE $\varepsilon 4$ carriers (Schuit et al., 2001; Rovio et al., 2005; Smith et al., 2011). 


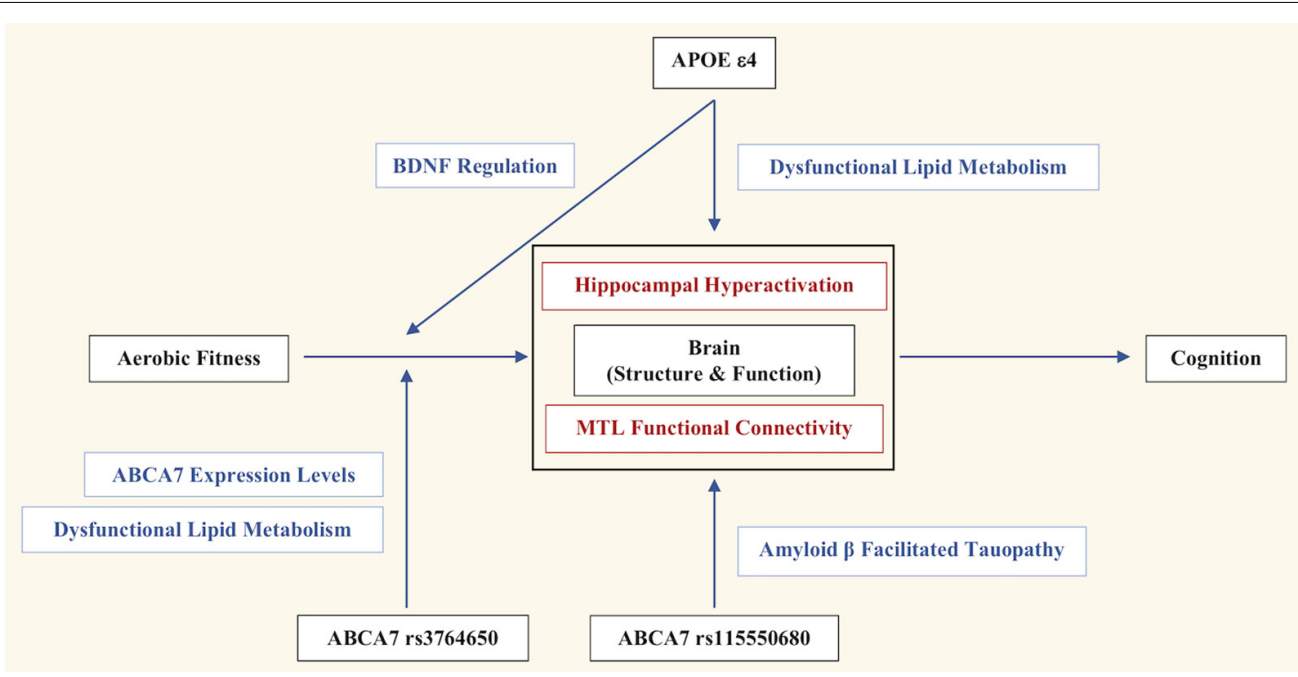

FIGURE 1 | The genetic and lifestyle factors that contribute to Alzheimer's disease (AD) risk and impaired cognitive function in African Americans. Overall, aerobic fitness influences brain structure and function, which then affects cognition. Apolipoprotein E (APOE) $\varepsilon 4$ directly impacts brain structure and function via dysfunctional lipid metabolism, leading to aberrant hippocampal hyperactivation and therefore, impaired mnemonic discrimination of episodic memories. APOE $\varepsilon 4$ indirectly influences the effects of aerobic exercise on hippocampal plasticity and volume through the regulation of BDNF. ABCA7 rs115550680 directly impacts the brain through amyloid- $\beta(A \beta)$ facilitated tauopathy, which negatively influences medial temporal lobe (MTL) functional connectivity, and consequently, behavioral generalization. ABCA7 rs3764650 moderates the effects of aerobic fitness through dysfunctional lipid metabolism and ABCA7 expression, which indirectly impairs behavioral generalization.

Additionally, in African Americans the APOE $\varepsilon 4$ genotype has been found to influence exercise-related upregulation of BDNF (brain-derived neurotrophic factor), a gene associated with neuroplasticity and hippocampal volume (Erickson et al., 2011); non-carriers of the $\varepsilon 4$ allele exclusively experienced a significant increase in BDNF levels after 6 months of exercise, while carriers did not (Allard et al., 2017).

Research on the interactive effects of aerobic fitness and genetic risk for $\mathrm{AD}$ is still in the early stages, with the various studies containing methodological and racial differences in subject populations. Albeit equivocal, these results do provide evidence of the modulating effect of genetic variation on modifiable $\mathrm{AD}$ risk factors.

\section{DISCUSSION}

Here, we reviewed research outlining the influence of genetic risk on MTL neural and cognitive function. We present a novel comprehensive outline of how genotypic variation may contribute to $\mathrm{AD}$ and impaired cognitive function (Figure 1). Overall, aerobic fitness influences neural structure and function, which then affects cognition. APOE $\varepsilon 4$ directly impacts the brain via dysfunctional lipid metabolism, leading to aberrant hippocampal hyperactivation, and therefore, impaired mnemonic discrimination of episodic memories (Sinha et al., 2018). The indirect effects of APOE $\varepsilon 4$ via fitness remain somewhat ambiguous, with some studies reporting aerobic fitness-related benefits only in APOE $\varepsilon 4-$ individuals (Podewils et al., 2005; Lautenschlager et al., 2008; Allard et al., 2017), while other studies report those benefits only in APOE $\varepsilon 4+$ individuals (Schuit et al., 2001; Rovio et al., 2005; Smith et al., 2011). However, exercise-induced upregulation of BDNF, and its influence on hippocampal plasticity, may serve as a possible mechanism for the indirect influence of APOE $\varepsilon 4$ (Allard et al., 2017).

Meanwhile, ABCA7 rs115550680 directly impacts the brain through $A \beta$ facilitated tauopathy, which negatively influences MTL functional connectivity, and consequently, behavioral generalization (Sinha et al., 2019). Although ABCA7 rs3764650 is not a causative variant for AD in African Americans, and does not directly impact brain structure and function, it appears to confer indirect consequences on cognition and $\mathrm{AD}$ risk by moderating the effects of aerobic fitness through dysfunctional lipid metabolism and ABCA7 expression (Berg et al., 2019).

While the current schematic (Figure 1) of genetic influences on $\mathrm{AD}$ risk in African Americans is a first step, additional studies are needed to verify the molecular mechanisms underlying the link between genetic risk and pathogenic pathways; the potential contribution of brain lipid homeostasis in the MTL should be a focal point. It is also important to determine if ABCA7 and APOE have any common pathways mediating the effect on MTL structure and function. Furthermore, comprehensive single-cell type transcriptome analyses in human and mouse brains may be necessary to determine cell-specific contributions of $\mathrm{ABCA} 7$ risk variants to $\mathrm{AD}$ pathogenesis. For instance, ABCA7 rs115550680-related dysregulation of lipid metabolism may specifically target the neurons accelerating APP processing and $A \beta$ production, while, ABCA7 rs3764650 may impact $\mathrm{A} \beta$ clearance by the microglia, known to play a pivotal role in mediating exercise-dependent enhancement of hippocampal neurogenesis (Vukovic et al., 2012). 
Several studies have shown qualitative and quantitative differences in $\mathrm{AD}$ between African Americans and European Americans. One such study found racial differences in cerebrospinal fluid (CSF) and structural MRI biomarkers of $\mathrm{AD}$ in an elderly cohort; despite comparable CSF A 342 levels, white matter hyperintensity (WMH) volume, and hippocampal volume, the same degree of $\mathrm{WMH}$ had a greater influence on cognition in African Americans as compared to European Americans (Howell et al., 2017). Since WMH is a marker of vascular dysfunction, which African Americans experience at a higher rate than European Americans (Obisesan et al., 2012), these results may indicate that genes such as APOE and ABCA7, which regulate lipid metabolism, differentially affect African Americans. For example, the direct and indirect effects of ABCA7 have not been validated in other racial groups. ABCA7 rs115550680 is monomorphic on the non-risk minor "A" allele in European Americans (Reitz et al., 2013; Machiela and Chanock, 2015). As such, ABCA7 rs115550680 may confer $\mathrm{AD}$ risk selectively in African Americans, and, in conjunction with the indirect effects of ABCA7 rs3764650, may contribute to the higher incidence rate of dementia and $\mathrm{AD}$ in this population.

\section{REFERENCES}

Aikawa, T., Holm, M.-L., and Kanekiyo, T. (2018). ABCA7 and pathogenic pathways of Alzheimer's disease. Brain Sci. 8:27. doi: 10.3390/brainsci8020027

Allard, J. S., Ntekim, O., Johnson, S. P., Ngwa, J. S., Bond, V., Pinder, D., et al. (2017). APOE\&4 impacts up-regulation of brain-derived neurotrophic factor after a six-month stretch and aerobic exercise intervention in mild cognitively impaired elderly African Americans: a pilot study. Exp. Gerontol. 87, 129-136. doi: 10.1016/j.exger.2016.11.001

Alzheimer's Association. (2019). 2019 Alzheimer's disease facts and figures. Alzheimers Dement. 15, 321-387. doi: 10.1016/j.jalz.2019.01.010

Andrews, S. J., Das, D., Anstey, K. J., and Easteal, S. (2017). Late onset alzheimer's disease risk variants in cognitive decline: the PATH through life study. J. Alzheimers Dis. 57, 423-436. doi: 10.3233/JAD-160774

Andrews, S. J., Das, D., Cherbuin, N., Anstey, K. J., and Easteal, S. (2016). Association of genetic risk factors with cognitive decline: the PATH through life project. Neurobiol. Aging 41, 150-158. doi: 10.1016/j.neurobiolaging.2016. 02.016

Bakker, A., Albert, M. S., Krauss, G., Speck, C. L., and Gallagher, M. (2015). Response of the medial temporal lobe network in amnestic mild cognitive impairment to therapeutic intervention assessed by fMRI and memory task performance. NeuroImage Clin. 7, 688-698. doi: 10.1016/j.nicl.2015. 02.009

Bakker, A., Krauss, G. L., Albert, M. S., Speck, C. L., Jones, L. R., Stark, C. E., et al. (2012). Reduction of hippocampal hyperactivity improves cognition in amnestic mild cognitive impairment. Neuron 74, 467-474. doi: 10.1016/j. neuron.2012.03.023

Barnes, L. L., and Bennett, D. A. (2014). Alzheimer's disease in African Americans: risk factors and challenges for the future. Health Aff. 33, 580-586. doi: 10.1377/hlthaff.2013.1353

Baumgart, M., Snyder, H. M., Carrillo, M. C., Fazio, S., Kim, H., and Johns, H. (2015). Summary of the evidence on modifiable risk factors for cognitive decline and dementia: a population-based perspective. Alzheimers Dement. 11, 718-726. doi: 10.1016/j.jalz.2015.05.016

Benjamin, E. J., Muntner, P., and Bittencourt, M. S. (2019). Heart disease and stroke statistics-2019 update: a report from the American Heart Association. Circulation 139, e56-e528. doi: 10.1161/CIR.0000000000000659

Berg, C. N., Sinha, N., and Gluck, M. A. (2019). ABCA7 risk genotype diminishes the neuroprotective value of aerobic fitness in healthy older African Americans. Front. Aging Neurosci. 11:73. doi: 10.3389/fnagi.2019.00073
It is imperative that the studies presented here be replicated across diverse subject populations for a more representative and comprehensive understanding of $\mathrm{AD}$ progression and outcomes. At the same time, it will be crucial for future studies to examine race-specific $\mathrm{AD}$ biomarkers and consequences. Finally, researchers should explore the interplay between genetic variation and other modifiable lifestyle factors, such as diet and sleep patterns, to understand whether the benefits of potential interventions are similar for those with and without a genetic risk for dementia and $\mathrm{AD}$.

\section{AUTHOR CONTRIBUTIONS}

$\mathrm{CB}$ and NS conducted background research. $\mathrm{CB}$ drafted the manuscript. NS and MG provided critical review of the manuscript.

\section{FUNDING}

Grants to MG from the NIH's National Institute on Aging (1R01AG053961) and the New Jersey Department of Health's Office of Minority and Multicultural Health (MH-STT-15-001).

Bondi, M. W., Salmon, D. P., Galasko, D., Thomas, R. G., and Thal, L. J. (1999). Neuropsychological function and apolipoprotein E genotype in the preclinical detection of Alzheimer's disease. Psychol. Aging 14, 295-303. doi: 10.1037//0882-7974.14.2.295

Bookheimer, S. Y., Strojwas, M. H., Cohen, M. S., Saunders, A. M., PericakVance, M. A., Mazziotta, J. C., et al. (2000). Patterns of brain activation in people at risk for Alzheimer's disease. N. Engl. J. Med. 343, 450-456. doi: 10.1056/NEJM200008173430701

Bunce, D., Fratiglioni, L., Small, B. J., Winblad, B., and Bäckman, L. (2004). APOE and cognitive decline in preclinical Alzheimer disease and non-demented aging. Neurology 63, 816-821. doi: 10.1212/01.wnl.0000137041.86153.42

Carrasquillo, M. M., Crook, J. E., Pedraza, O., Thomas, C. S., Pankratz, V. S., Allen, M., et al. (2015). Late-onset Alzheimer's risk variants in memory decline, incident mild cognitive impairment and Alzheimer's disease. Neurobiology of Aging 36, 60-67. doi: 10.1016/j.neurobiolaging.2014.07.042

Caselli, R. J., Graff-Radford, N. R., Reiman, E. M., Weaver, A., Osborne, D., Lucas, J., et al. (1999). Preclinical memory decline in cognitively normal apolipoprotein E- 44 homozygotes. Neurology 53, 201-207. doi: 10.1212/wnl. 53.1.201

Cass, S. P. (2017). Alzheimer's disease and exercise: a literature review. Curr. Sports Med. Rep. 16, 19-22. doi: 10.1249/JSR.0000000000000332

Colcombe, S. J., and Kramer, A. F. (2003). Fitness effects on the cognitive function of older adults: a meta-analytic study. Psychol. Sci. 14, 125-130. doi: 10.1111/1467-9280.t01-1-01430

Cotman, C. W., Berchtold, N. C., and Christie, L.-A. (2007). Exercise builds brain health: key roles of growth factor cascades and inflammation. Trends Neurosci. 30, 464-472. doi: 10.1016/j.tins.2007.06.011

Cukier, H. N., Kunkle, B. W., Vardarajan, B. N., Rolati, S., HamiltonNelson, K. L., Kohli, M. A., et al. (2016). ABCA7 frameshift deletion associated with Alzheimer disease in African Americans. Neurol. Genet. 2:e79. doi: 10.1212/NXG.0000000000000079

Das, S. R., Pluta, J., Mancuso, L., Kliot, D., Orozco, S., Dickerson, B. C., et al. (2013). Increased functional connectivity within medial temporal lobe in mild cognitive impairment. Hippocampus 23, 1-6. doi: 10.1002/hipo.22051

Dennis, N. A., Browndyke, J. N., Stokes, J., Need, A., Burke, J. R., WelshBohmer, K. A., et al. (2010). Temporal lobe functional activity and connectivity in young adult APOE $\varepsilon 4$ carriers. Alzheimers Dement. 6, 303-311. doi: 10.1016/j.jalz.2009.07.003

Dickerson, B. C., Salat, D. H., Greve, D. N., Chua, E. F., Rand-Giovannetti, E., Rentz, D. M., et al. (2005). Increased hippocampal activation in mild cognitive 
impairment compared to normal aging and AD. Neurology 65, 404-411. doi: 10.1212/01.wnl.0000171450.97464.49

Di Paolo, G., and Kim, T.-W. (2011). Linking lipids to Alzheimer's disease: cholesterol and beyond. Nat. Rev. Neurosci. 12:484. doi: 10.1038/nrn3075

Elias-Sonnenschein, L. S., Viechtbauer, W., Ramakers, I. H. G. B., Verhey, F. R. J., and Visser, P. J. (2011). Predictive value of APOE- 44 allele for progression from MCI to AD-type dementia: a meta-analysis. J. Neurol. Neurosurg. Psychiatry 82, 1149-1156. doi: 10.1136/jnnp.2010.231555

Erickson, K. I., Voss, M. W., Prakash, R. S., Basak, C., Szabo, A., Chaddock, L., et al. (2011). Exercise training increases size of hippocampus and improves memory. Proc. Natl. Acad. Sci. U S A 108, 3017-3022. doi: 10.1073/pnas.10159 50108

Farrer, L. A., Cupples, L. A., Haines, J. L., Hyman, B., Kukull, W. A., Mayeux, R., et al. (1997). Effects of age, sex and ethnicity on the association between apolipoprotein E genotype and Alzheimer disease: a meta-analysis. JAMA 278, 1349-1356. doi: 10.1001/jama.1997.03550160069041

Filippini, N., MacIntosh, B. J., Hough, M. G., Goodwin, G. M., Frisoni, G. B., Smith, S. M., et al. (2009). Distinct patterns of brain activity in young carriers of the APOE- 44 allele. Proc. Natl. Acad. Sci. U S A 106, 7209-7214. doi: 10.1073/pnas.0811879106

Gothe, N. P., and Kendall, B. J. (2016). Barriers, motivations and preferences for physical activity among female african american older adults. Gerontol. Geriatr. Med. 2:233372141667739. doi: 10.1177/2333721416677399

Hardy, J., and Selkoe, D. J. (2002). The amyloid hypothesis of Alzheimer's disease: progress and problems on the road to therapeutics. Science 297, 353-356. doi: $10.1126 /$ science.1072994

He, X., Liu, D., Zhang, Q., Liang, F., Dai, G., Zeng, J., et al. (2017). Voluntary exercise promotes glymphatic clearance of amyloid beta and reduces the activation of astrocytes and microglia in aged mice. Front. Mol. Neurosci. 10:144. doi: 10.3389/fnmol.2017.00144

Hendrie, H. C., Murrell, J., Baiyewu, O., Lane, K. A., Purnell, C., Ogunniyi, A., et al. (2014). APOE $\varepsilon 4$ and the risk for Alzheimer disease and cognitive decline in African Americans and Yoruba. Int. Psychogeriatr. 26, 977-985. doi: $10.1017 /$ S1041610214000167

Hollingworth, P., Harold, D., Sims, R., Gerrish, A., Lambert, J.-C., Carrasquillo, M. M., et al. (2011). Common variants at ABCA7, MS4A6A/MS4A4E, EPHA1, CD33 and CD2AP are associated with Alzheimer's disease. Nat. Genet. 43:429. doi: 10.1038/ng.803

Houdebine, L., Gallelli, C. A., Rastelli, M., Sampathkumar, N. K., and Grenier, J. (2017). Effect of physical exercise on brain and lipid metabolism in mouse models of multiple sclerosis. Chem. Phys. Lipids 207, 127-134. doi: 10.1016/j. chemphyslip.2017.06.002

Howell, J. C., Watts, K. D., Parker, M. W., Wu, J., Kollhoff, A., Wingo, T. S., et al. (2017). Race modifies the relationship between cognition and Alzheimer's disease cerebrospinal fluid biomarkers. Alzheimers Res. Ther. 9:88. doi: 10.1186/s13195-017-0315-1

Izquierdo-Porrera, A. M., and Waldstein, S. R. (2002). Cardiovascular risk factors and cognitive function in African Americans. J. Gerontol. B Psychol. Sci. Soc. Sci. 57, P377-P380. doi: 10.1093/geronb/57.4.p377

Karch, C. M., Jeng, A. T., Nowotny, P., Cady, J., Cruchaga, C., and Goate, A. M. (2012). Expression of novel Alzheimer's disease risk genes in control and Alzheimer's disease brains. PLOS One 7:e50976. doi: 10.1371/journal.pone. 0050976

Kramer, A. F., Colcombe, S. J., McAuley, E., Scalf, P. E., and Erickson, K. I. (2005). Fitness, aging and neurocognitive function. Neurobiol. Aging 26, 124-127. doi: 10.1016/j.neurobiolaging.2005.09.009

Kramer, A. F., Erickson, K. I., and Colcombe, S. J. (2006). Exercise, cognition and the aging brain. J. Appl. Physiol. 101, 1237-1242. doi: 10.1152/japplphysiol. 00500.2006

Lautenschlager, N. T., Cox, K. L., Flicker, L., Foster, J. K., van Bockxmeer, F. M., Xiao, J., et al. (2008). Effect of physical activity on cognitive function in older adults at risk for Alzheimer disease: a randomized trial. JAMA 300, 1027-1037. doi: 10.1001/jama.300.9.1027

Leal, S. L., and Yassa, M. A. (2018). Integrating new findings and examining clinical applications of pattern separation. Nat. Neurosci. 21, 163-173. doi: 10.1038/s41593-017-0065-1

Logue, M. W., Schu, M., Vardarajan, B. N., Buros, J., Green, R. C., Go, R. C. P., et al. (2011). A comprehensive genetic association study of Alzheimer disease in african americans. Arch. Neurol. 68, 1569-1579. doi: 10.1001/archneurol. 2011.646

Machiela, M. J., and Chanock, S. J. (2015). LDlink: a web-based application for exploring population-specific haplotype structure and linking correlated alleles of possible functional variants. Bioinformatics 31, 3555-3557. doi: 10.1093/bioinformatics/btv402

Maesako, M., Uemura, K., Kubota, M., Kuzuya, A., Sasaki, K., Hayashida, N., et al. (2012). Exercise is more effective than diet control in preventing high fat diet-induced $\beta$-amyloid deposition and memory deficit in amyloid precursor protein transgenic mice. J. Biol. Chem. 287, 23024-23033. doi: 10.1074/jbc. M112.367011

Michaelson, D. M. (2014). APOE $\varepsilon 4$ : the most prevalent yet understudied risk factor for Alzheimer's disease. Alzheimers Dement. 10, 861-868. doi: 10.1016/j. jalz.2014.06.015

Mormino, E. C., Betensky, R. A., Hedden, T., Schultz, A. P., Ward, A., Huijbers, W., et al. (2014). Amyloid and APOE $\varepsilon 4$ interact to influence short-term decline in preclinical Alzheimer disease. Neurology 82, 1760-1767. doi: 10.1212/WNL.0000000000000431

Myers, C. E., Kluger, A., Golomb, J., Ferris, S., de Leon, M. J., Schnirman, G., et al. (2002). Hippocampal atrophy disrupts transfer generalization in non-demented elderly. J. Geriatr. Psychiatry Neurol. 15, 82-90. doi: $10.1177 / 089198870201500206$

Myers, C. E., Kluger, A., Golomb, J., Gluck, M. A., and Ferris, S. (2008). Learning and generalization tasks predict short-term cognitive outcome in nondemented elderly. J. Geriatr. Psychiatry Neurol. 21, 93-103. doi: $10.1177 / 0891988708316858$

Naj, A. C., Jun, G., Beecham, G. W., Wang, L.-S., Vardarajan, B. N., Buros, J., et al. (2011). Common variants at MS4A4/MS4A6E, CD2AP, CD33 and EPHA1 are associated with late-onset Alzheimer's disease. Nat. Genet. 43, 436-441. doi: 10.1038/ng.801

Nettiksimmons, J., Tranah, G., Evans, D. S., Yokoyama, J. S., and Yaffe, K. (2016). Gene-based aggregate SNP associations between candidate AD genes and cognitive decline. Age 38:41. doi: 10.1007/s11357-016-9885-2

Norton, S., Matthews, F. E., Barnes, D. E., Yaffe, K., and Brayne, C. (2014). Potential for primary prevention of Alzheimer's disease: an analysis of population-based data. Lancet Neurol. 13, 788-794. doi: 10.1016/S14744422(14)70136-X

Obisesan, T. O., Gillum, R. F., Johnson, S., Umar, N., Williams, D., Bond, V., et al. (2012). Neuroprotection and neurodegeneration in Alzheimer's disease: role of cardiovascular disease risk factors, implications for dementia rates and prevention with aerobic exercise in african americans. Int. J. Alzheimers Dis. 2012:568382. doi: $10.1155 / 2012 / 568382$

Palmer, A., and Good, M. (2011). Hippocampal synaptic activity, pattern separation and episodic-like memory: implications for mouse models of Alzheimer's disease pathology. Biochem. Soc. Trans. 39, 902-909. doi: 10.1042/bst0390902

Pasquini, L., Scherr, M., Tahmasian, M., Meng, C., Myers, N. E., Ortner, M., et al. (2015). Link between hippocampus' raised local and eased global intrinsic connectivity in AD. Alzheimers Dement. 11, 475-484. doi: 10.1016/j.jalz.2014. 02.007

Podewils, L. J., Guallar, E., Kuller, L. H., Fried, L. P., Lopez, O. L., Carlson, M., et al. (2005). Physical activity, APOE genotype and dementia risk: findings from the cardiovascular health cognition study. Am. J. Epidemiol. 161, 639-651. doi: 10.1093/aje/kwi092

Pooler, A. M., Polydoro, M., Maury, E. A., Nicholls, S. B., Reddy, S. M., Wegmann, S., et al. (2015). Amyloid accelerates tau propagation and toxicity in a model of early Alzheimer's disease. Acta Neuropathol. Commun. 3:14. doi: $10.1186 / \mathrm{s} 40478-015-0199-\mathrm{x}$

Potter, H., and Wisniewski, T. (2012). Apolipoprotein E: essential catalyst of the Alzheimer amyloid cascade. Int. J. Alzheimers Dis. 2012:489428. doi: 10.1155/2012/489428

Rajabli, F., Feliciano, B. E., Celis, K., Hamilton-Nelson, K. L., Whitehead, P. L., Adams, L. D., et al. (2018). Ancestral origin of APOE $\varepsilon 4$ Alzheimer disease risk in Puerto Rican and African American populations. PLoS Genet. 14:e1007791. doi: 10.1371/journal.pgen.1007791

Reagh, Z. M., Noche, J. A., Tustison, N., Delisle, D., Murray, E. A., and Yassa, M. A. (2017). Anterolateral entorhinal-hippocampal imbalance in older adults disrupts object pattern separation. bioRxiv [Preprint]. doi: 10.1101/162925 
Reitz, C., Jun, G., Naj, A., Rajbhandary, R., Vardarajan, B. N., Wang, L. S., et al. (2013). Variants in the atp-binding cassette transporter (abca7), Apolipoprotein E $\varepsilon 4$ and the risk of late-onset alzheimer disease in african americans. JAMA 309, 1483-1492. doi: 10.1001/jama.2013.2973

Rovio, S., Kåreholt, I., Helkala, E.-L., Viitanen, M., Winblad, B., Tuomilehto, J., et al. (2005). Leisure-time physical activity at midlife and the risk of dementia and Alzheimer's disease. Lancet Neurol. 4, 705-711. doi: 10.1016/S14744422(05)70198-8

Schuit, A. J., Feskens, E. J. M., Launer, L. J., and Kromhout, D. (2001). Physical activity and cognitive decline, the role of the Apolipoprotein e4 allele. Med. Sci. Sports Exerc. 33, 772-777. doi: 10.1097/00005768-200105000-00015

Schultz, S. A., Boots, E. A., Darst, B. F., Zetterberg, H., Blennow, K., Edwards, D. F., et al. (2017). Cardiorespiratory fitness alters the influence of a polygenic risk score on biomarkers of AD. Neurology 88, 1650-1658. doi: 10.1212/wnl. 0000000000003862

Sheppard, D. P., Graves, L. V., Holden, H. M., Delano-Wood, L., Bondi, M. W., and Gilbert, P. E. (2016). Spatial pattern separation differences in older adult carriers and non-carriers for the apolipoprotein E epsilon 4 allele. Neurobiol. Learn. Mem. 129, 113-119. doi: 10.1016/j.nlm.2015.04.011

Sinha, N., Berg, C. N., Tustison, N. J., Shaw, A., Hill, D., Yassa, M. A., et al. (2018). APOE $\varepsilon 4$ status in healthy older African Americans is associated with deficits in pattern separation and hippocampal hyperactivation. Neurobiol. Aging 69, 221-229. doi: 10.1016/j.neurobiolaging.2018.05.023

Sinha, N., Reagh, Z. M., Tustison, N. J., Berg, C. N., Shaw, A., Myers, C. E., et al. (2019). ABCA7 risk variant in healthy older African Americans is associated with a functionally isolated entorhinal cortex mediating deficient generalization of prior discrimination training. Hippocampus 29, 527-538. doi: 10.1002/hipo. 23042

Smith, J. C., Nielson, K. A., Woodard, J. L., Seidenberg, M., Durgerian, S., Antuono, P., et al. (2011). Interactive effects of physical activity and APOE$\varepsilon 4$ on BOLD semantic memory activation in healthy elders. Neuroimage 54, 635-644. doi: 10.1016/j.neuroimage.2010.07.070

Song, Z., Insel, P. S., Buckley, S., Yohannes, S., Mezher, A., Simonson, A., et al. (2015). Brain amyloid- $\beta$ burden is associated with disruption of intrinsic functional connectivity within the medial temporal lobe in cognitively normal elderly. J. Neurosci. 35, 3240-3247. doi: 10.1523/JNEUROSCI.2092-14.2015

Stark, S. M., Yassa, M. A., Lacy, J. W., and Stark, C. E. L. (2013). A task to assess behavioral pattern separation (BPS) in humans: data from healthy aging and mild cognitive impairment. Neuropsychologia 51, 2442-2449. doi: 10.1016/j. neuropsychologia.2012.12.014

Tang, M.-X., Cross, P., Andrews, H., Jacobs, D. M., Small, S., Bell, K., et al. (2001). Incidence of AD in African Americans, Caribbean hispanics, and caucasians in northern Manhattan. Neurology 56, 49-56. doi: 10.1212/wnl.56.1.49

Toner, C. K., Pirogovsky, E., Kirwan, C. B., and Gilbert, P. E. (2009). Visual object pattern separation deficits in nondemented older adults. Learn. Mem. 16, 338-342. doi: 10.1101/lm.1315109
Tran, T. T., Speck, C. L., Pisupati, A., Gallagher, M., and Bakker, A. (2017). Increased hippocampal activation in ApoE-4 carriers and non-carriers with amnestic mild cognitive impairment. Neuroimage Clin. 13, 237-245. doi: 10.1016/j.nicl.2016.12.002

Vasquez, J. B., Fardo, D. W., and Estus, S. (2013). ABCA7 expression is associated with Alzheimer's disease polymorphism and disease status. Neurosci. Lett. 556, 58-62. doi: 10.1016/j.neulet.2013.09.058

Vivot, A., Glymour, M. M., Tzourio, C., Amouyel, P., Chêne, G., and Dufouil, C. (2015). Association of Alzheimer's related genotypes with cognitive decline in multiple domains: results from the Three-City Dijon study. Mol. Psychiatry 20, 1173-1178. doi: 10.1038/mp.2015.62

Vukovic, J., Colditz, M. J., Blackmore, D. G., Ruitenberg, M. J., and Bartlett, P. F. (2012). Microglia modulate hippocampal neural precursor activity in response to exercise and aging. J. Neurosci. 32, 6435-6443. doi: 10.1523/jneurosci.592511.2012

Wesnes, K. A., Annas, P., Basun, H., Edgar, C., and Blennow, K. (2014). Performance on a pattern separation task by Alzheimer's patients shows possible links between disrupted dentate gyrus activity and apolipoprotein $\mathrm{E}$ $\varepsilon 4$ status and cerebrospinal fluid amyloid- $\beta 42$ levels. Alzheimers Res. Ther. 6:20 doi: 10.1186/alzrt250

Yassa, M. A., Lacy, J. W., Stark, S. M., Albert, M. S., Gallagher, M., and Stark, C. E. L. (2011a). Pattern separation deficits associated with increased hippocampal CA3 and dentate gyrus activity in nondemented older adults. Hippocampus 21, 968-979. doi: 10.1002/hipo.20808

Yassa, M. A., Mattfeld, A. T., Stark, S. M., and Stark, C. E. L. (2011b). Age-related memory deficits linked to circuit-specific disruptions in the hippocampus. Proc. Natl. Acad. Sci. U S A 108, 8873-8878. doi: 10.1073/pnas.1101 567108

Yassa, M. A., Stark, S. M., Bakker, A., Albert, M. S., Gallagher, M., and Stark, C. E. L. (2010). High-resolution structural and functional MRI of hippocampal CA3 and dentate gyrus in patients with amnestic mild cognitive impairment. Neuroimage 51, 1242-1252. doi: 10.1016/j.neuroimage.2010. 03.040

Zhao, Q.-F., Yu, J.-T., Tan, M.-S., and Tan, L. (2015). ABCA7 in Alzheimer's disease. Mol. Neurobiol. 51, 1008-1016. doi: 10.1007/s12035-014-8759-9

Conflict of Interest: The authors declare that the research was conducted in the absence of any commercial or financial relationships that could be construed as a potential conflict of interest.

Copyright (c) 2019 Berg, Sinha and Gluck. This is an open-access article distributed under the terms of the Creative Commons Attribution License (CC BY). The use, distribution or reproduction in other forums is permitted, provided the original author(s) and the copyright owner(s) are credited and that the original publication in this journal is cited, in accordance with accepted academic practice. No use, distribution or reproduction is permitted which does not comply with these terms. 